\title{
Language diaries in the study of language use and language choice: the case of Flemish
}

\section{Sign Language and Scottish Gaelic}

Maartje De Meulder* ${ }_{1}$ and Ingeborg Birnie**

*University of Namur, Namur Institute of Language, Text and Transmediality (NaLTT), Rue de Bruxelles 61, 5000 Namur, Belgium.

maartje.demeulder@hu.nl

Twitter: @mdemeulder

**University of Strathclyde, School of Education, 141 St James Road, Glasgow, G4 OLT United Kingdom

Ingeborg.birnie@strath.ac.uk

\section{Abstract}

This article discusses the rationale for using language diaries as a method to evaluate language use and language choice in multilingual contexts, as well as the benefits and limitations of this approach vis-à-vis other research methods. This is illustrated using examples from two contexts: Flemish Sign Language/Dutch bilinguals in Flanders and Gaelic/English bilinguals in the Western Isles of Scotland. In both cases, the language diaries were part of a larger mixed-method study which aimed to evaluate language use and language choice in contexts in which the majority language is in almost all instances the unmarked choice. Language diaries provide a new perspective on individual language practices as they allow for an evaluation of contextualised examples of language use and give insight into the factors that drive language and modality choice, and language ideologies. Language diaries give participants ownership over the information shared with the researcher

${ }^{1}$ Current affiliation: Faculty of Healthy and Sustainable Living, University of Applied Sciences Utrecht, the Netherlands. 
and provide access to a number of different domains. Despite being based on self-reported practices, their situated nature demonstrates how language use can change through personal circumstances. This in turn contributes to a greater understanding of the use of Flemish Sign Language and Gaelic in the wider sociolinguistic contexts in which these languages exist.

Keywords: language choice, Gaelic, sign language, deaf, minority language, language diaries

\section{Introduction}

Language diaries have been described as 'ethnographic self-reports of daily speech encounters' (Starks \& Lee, 2010, p. 233). In this article the term language diary will be used to describe a method of ethnographic data collection where participants are asked to selfreport on their linguistic encounters for a period of time.

Language diaries have been used to collect information about linguistic practices, and in particular the language choice and language use of bi- or plurilinguals (see, for example, de Bres, 2014; Gibbons, 1987; Jones et al., 2000; Lamarre, 2013; Lawson \& Sachdev, 2000; Place \& Hoff, 2011; Romaine, 1983; Starks \& Lee, 2010; Sundqvist \& Sylvén, 2014; Ure, 1979). All these studies used solicited entries and selected or recruited participants to report on their use of language and provide contextual information on these encounters. The manner in which language diaries have been conceptualised in these studies has varied; ranging from asking participants to keep a series of notes with open-ended responses to a more structured approach using templates.

We have both used language diaries as part of a larger mixed-method study. For Study 1, Maartje focused on the language practices and language ideologies of deaf and hearing signers in Flanders, the northern region of Belgium, and how these are linked to the 
sociolinguistic vitality of Flemish Sign Language (VGT). This study used language diaries to supplement data collected through interviews and language portraits (Kusters \& De Meulder, 2019). In Study 2 Ingeborg used the language diaries as part of a wider study on Gaelic language use and language choice and communal linguistic practices in Stornoway, the largest settlement in the Western Isles of Scotland. In this study, the diaries were used to supplement data collected through interviews and ethnographic language use surveys in public spaces. These language use surveys, based on the model developed in the Basque Country (Altuna \& Basurto, 2013) provide a quantitative method of identifying the main languages used, as well as the demographic profile of the speakers, in conversations in public spaces (see Birnie, 2018).

To our knowledge, our studies were the first to use this methodological approach in these specific contexts. Previous studies on the use of Gaelic have focused to a large extent on data collection through questionnaires and (structured) interviews with individuals within a particular speech community. These studies typically asked participants to identify the frequency of the minority language use in a range of social contexts and situations, in many instances relying on a Likert scale (e.g. MacKinnon, 1977; Munro et al., 2010; NicAoidh, 2006) with follow-up interviews to further elicit information on (minority) language practices. Sociolinguistic studies on language use and language choice of VGT in different contexts are still scarce (but see De Meulder et al. (2017) and Van Herreweghe \& Vermeerbergen (2004)).

The nature of these research methods mean that the information provided by participants is often based on retrospection (Hyers, 2018), which, according to Bolger et al. (2013, p. 585) might lead to aggregate or generalised responses 'that reflect faulty reconstruction of the phenomena of interest'. Urla (2013) has suggested that questionnaires and interviews might be particularly prone to what has been described as the "phenomenon of 
misplaced scale': when reporting on minority language use, participants in these studies are more likely to recall speech encounters or instances where the minority language was used rather than the majority language as these were the interactions which were more unusual and therefore stood out. Bourhis and Sachdev (1984) have further suggested that the reporting of minority language use is also likely to be influenced by the political and social circumstances of languages, and the particular perception and language ideologies of the research participants.

Other studies on language use have applied ethnographic data collection methods with data collected by the researcher, for example through applying the 'go-along' method (Kusenbach, 2003; Lamarre, 2013) which involves a researcher accompanying the participants as they go about their daily routine, either recording interactions in situ or elicit information on interactions retrospectively. A further example of a study which aimed to capture speech encounters as they occurred rather than relying on aggregate and retrospective responses was Smith-Christmas' (2016) study of family language policy which used ethnographic observations supported by audio recordings of naturally occurring conversations between family members in a home environment. In these studies, the researcher collects data through notes or recordings. This raises questions surrounding the inclusion and exclusion criteria applied, both in the data collection and analysis of the interactions. The presence of the researcher might also influence the linguistic practices of the participants, as well as the interlocutors. Therefore Nandi (2016), also in the domain of family language policy, used a variant to language diaries, called 'family language audits', involving observation checklists and self-recorded audio footage by families without the researcher present, to understand language practices in multilingual families.

Language diaries, like the methodological approaches discussed above, can be used to provide information about a wide range of contexts and situations. Unlike questionnaires and 
interviews, they do not rely on aggregate responses, instead asking participants to record each encounter as an individual instance of an interaction. Whereas 'go-alongs' and (most) ethnographic audio- and or video-recordings rely on the researcher reporting and selecting the encounters for inclusion, in language diaries participants are the agents of the data collection. This means that they have full ownership of any information that is shared with the researcher, providing choice and control (Pennington et al., 2014; Starks \& Lee, 2010). Furthermore, allowing participants to record their own data '[eliminates] the filter of the second person' (Palmer, 1928, p. 181, cited in Hyers, 2018). This feature of language diaries might also be used to reveal participants' ideologies and motivations, with Pennington et al. (2014, p. 79) identifying that 'it is to be expected that a person filling out a diary that focusses on language may be led by the underlying values and frames of reference to over- or under-report use of a certain language or variety'. The action of completing the language diary might, by itself, alter participants' linguistic practices by drawing attention to the language choices made, especially, perhaps, in studies which are conducted over a relatively short period of time.

In this article we discuss, in the specific context of our studies, the rationale for using language diaries as a data collection method and as a prompt to evaluate the linguistic practices of participants through interviews. We also discuss the benefits and limitations of language diaries vis-à-vis other quantitative and qualitative research methods to evaluate language use and language choice such as questionnaires, interviews, go-alongs and ethnographic filming. First, we sketch the sociolinguistics contexts of Gaelic and VGT, languages which, despite their different sociolinguistic contexts, face similar challenges in terms of assessing language use. 


\section{Sociolinguistic contexts}

Flemish Sign Language (Vlaamse Gebarentaal, VGT) is the main signed language used by deaf and hearing signers in Flanders, the northern part of Belgium. VGT was banned from the formal education system until the 1970s. This period of 'oralism' resulted in VGT not being used or developed outside Gemeinschaft, or community domains but it continued to be used in private domains, for example deaf people's homes, dorms of deaf residential schools and deaf clubs. The use of VGT in public administration, broadcasting, and the education system remains limited, and is most often mediated through sign language interpreters. In 2006, the Flemish Parliament legally recognised VGT as a language in the Flemish community and the bilingual region of Brussels-Capital. However, VGT is not a constitutionally recognised official language in Belgium like Dutch, French and German, and the 2006 decree merely entails recognition of the language as a cultural means, not the protection of the people who sign it.

Gaelic in Scotland is typically spoken by less than $2.0 \%$ of the population, with the exception of the Western Isles (where the language diary study was conducted). The Western Isles, consisting of eleven inhabited islands on the west coast of Scotland, can be described as the last remaining 'heartland' of the language with $52.2 \%$ of the population self-reporting to be able to speak Gaelic (National Records of Scotland, 2013). Gaelic has traditionally been associated with Gemeinschaft domains, but since the 1980s its use has been promoted in domains described by Fishman as "higher order props" (1991, p. 380): education, the media, and language management initiatives. Currently, Gaelic is offered as a subject and a medium of instruction in the education system and is available from pre-school to higher education. 
In 2005, the Scottish Parliament ratified the Gaelic Language (Scotland) Act which secured the status of Gaelic as 'an official language of Scotland commanding equal respect to the English language' (Scottish Parliament, 2005). The provisions of this Act require a National Plan for Gaelic to be prepared every five years and public authorities based in Scotland can be asked to produce a Gaelic language plan in which they are expected to set out measures to increase and facilitate the use of the language within the organisation. The Act has, however, not created any rights to use the language in public domain interactions when accessing or interacting with services.

Both Gaelic in Scotland and VGT in Flanders have thus received some form of legal and institutional recognition, although the tangible effects of this in terms of linguistic policies and practices remain limited (Birnie, 2018; De Meulder \& Haesenne, 2019). Speakers of Gaelic and signers of VGT are (at least) bilingual in Gaelic and English (Dunbar, 2011) and VGT and Dutch respectively. This, therefore, raises the question of how the use of Gaelic and VGT is imagined and translated into linguistic practices in a wide range of domains where the majority language is in almost all instances the unmarked choice (MyersScotton, 1988).

\section{Language diaries in the study of VGT and Gaelic language use}

In this section, we discuss how we recruited participants for our respective studies, the diary templates we used, instructions we gave participants for completing the diary, and how we analysed and evaluated the diaries. 


\section{Participant recruitment}

As both our studies used solicited language diary entries, we had to recruit participants who would be able and willing to commit to the completion of the diary for a specified period. Participants might perceive language diaries as time-consuming (Bolger et al., 2003) and since they cover a wide range of domains and situations, including intimate domains such as the home and family, there might be a reluctance on the part of participants to disclose this potentially sensitive or private information.

Maartje, who is deaf herself and has an extensive deaf social network, recruited informants through approaching potential participants directly. She selected informants based on their hearing status (and that of their family), linguistic trajectory, age, residence, motivation to participate and the extent to which they were perceived to be able to reflect on their linguistic practices. This resulted in a high proportion of the deaf VGT participants (five out of ten) being actively involved with VGT as part of their working environment, in contexts where the use of VGT is in most cases the unmarked choice. Individuals working in these environments are also more likely to be involved in language teaching, research, and advocacy, and a such tend to have a greater experience and opportunity to reflect on their language use and practices.

In total, Study 1 included thirteen participants, ten of which were deaf signers and the remaining three were hearing signers, ranging in age from 18 to 62 years. Most participants were known to Maartje before the study. This had specific consequences in terms of methodology and trust between participants and researcher. One participant told Maartje before the study that she actually was a bit afraid to be 'exposed', since she only ever had met Maartje in contexts where everyone signed, while actually in some context she used speech. 
The hearing signers in Study 1 were either partners of deaf people or hearing parents of deaf children. Three of the participants had partners who also participated in the study. As a result of a strong medical discourse in Flanders discouraging hearing parents to sign (Matthijs et al., 2017) and the fact that $95 \%$ of deaf children are being born into hearing non-signing families (Mitchell \& Karchmer, 2004), only a minority of the deaf participants acquired VGT through intergenerational transmission in the home. Most acquired VGT either through community exposure, in a deaf residential school, or through formal courses, although the majority of deaf participants now use VGT (or another sign language) at home with their partner and/or children.

In Study 2, participant recruitment proved to be more complicated. Ingeborg is a new speaker of Gaelic (see McLeod \& O’Rourke, 2015) and did not have a natural Gaelic network in the location of the study. Gaelic participants were recruited through word-ofmouth, personal contact with other researchers and active approaches to organisations involved in the Gaelic sectors, typically the media, education and language development. Just as with Study 1, this approach resulted in a high proportion of the informants being actively involved in Gaelic as part of their daily working environment.

The participant demographic in both these studies may, therefore, have influenced the overall use of VGT and Gaelic respectively, not only in the occupational but also in the private domain, with these individuals being more likely to have created minority language social networks (MacLeod, 2008). 
In Study 2, eleven Gaelic participants aged between 16 and 65 completed the study2. Four of these participants self-identified as new speakers and had not acquired Gaelic through intergenerational transmission, but instead through (adult) learning opportunities in the (formal) education system. In the sociolinguistic context of the community in which the research was conducted, all of these new speakers had some family connection to the language, but not necessarily within the parental home itself. This means that the distinction between L1 speakers, those who acquired the language (mainly) through intergenerational transmission, and new speakers, was not as clearly defined as might have been the case in other speech communities.

\section{Diary templates}

Both studies used a similar diary template based on those used by Starks and Lee (2010). Participants were provided with a grid-layout template to provide a structure and also to identify the particular elements of the interaction of interest to the respective studies. The templates allowed participants to record the language(s) used or note other ways of communication, information about the interlocutors (broad demographic profile, relationship to the diarist), the topic of the conversation and the space or situation in which the interaction took place. In Study 1, VGT participants were also asked to note down the hearing status of the interlocutor(s) (in case this was known) as well as the time and duration of the interaction, while Study 2 did not solicit information around the length of interactions. Both studies provided space in the templates for the participants to record any additional notes. The labels in Study 1 were in Dutch while those in Study 2 were in Gaelic. We are aware that the layout of the template reflects our agendas and that the labels reflect the categories we use as researchers but were confident that they were sufficiently open to allow participants to

${ }^{2}$ A total of fourteen participants had been recruited at the start of the study but due to a variety of different circumstances three participants did not return their diary for analysis. 
provide their own accounts, in combination with the instructions we gave them in person, and the interviews.

[Figure 1]

[Figure 2]

In both studies participants were asked to select at least seven, preferably consecutive, days in which to complete the diary. The length of this period was selected to recognise the importance of sustained cooperation of participants (Pennington et al., 2014), while also making the duration long enough to capture the different interactions that might take place over a typical week, including occupational domain interactions as well as private, public and educational interactions.

Participants were free to decide which seven days to select. In both studies a number of participants offered to select a period in which they were aware that they would have a higher than average number of VGT/Gaelic interactions. In this case we suggested that the selected week should reflect, as much as possible, a normal week in terms of linguistic practices and where they would be able to complete the diaries. Maartje sometimes attended an event where a VGT participant was also present, and which was later included in the diary. This provided her with an opportunity to make observations of the particular situation and allowed for data triangulation. In Study 2, the period in which Gaelic participants completed the diaries coincided with a period of Ingeborg's fieldwork when she was collecting other data on linguistic practices in the particular speech community in which the diary participants were living. This meant that on a number of occasions the Gaelic participants were also 
observed in the linguistic soundscape surveys (see Birnie, 2018) - allowing for triangulation of the diary data with other observations.

Instructions for completing the diary

Participants in both studies were provided with instructions on how to complete the diary template during an introductory one-to-one meeting. The aim and purpose of the research was explained, and the opportunity offered to either complete the diary entries on paper or as an electronic version. The 'unit of measurement' was also explained. In Study 1, VGT participants were asked to record 'conversations' where a conversation was defined as any interaction with other interlocutors both face-to-face and online. For face-to-face conversations in the analysis a distinction was made between short formal exchanges like greetings or placing orders or other quick exchanges with two or three turns and any conversations which were more extended. The short exchanges are typically characterised by limited or no prior acquaintance and participants most likely have to actively negotiate language and modality choice.

Study 1, following de Bres and Franziskus (2014), also asked VGT participants to include reading and writing. Since VGT does not have a widely used written form, it was hypothesised that it would mainly be used as a conversational language, while other languages would feature more dominantly in reading, writing or speaking, or combinations of these. Study 1 specifically asked VGT participants to also include online communication (for example recording a video and sending it through WhatsApp, calling someone on FaceTime, typing a text message) because VGT signers do not live in a dense community in the same geographical location, and it was expected that the electronic domain was one domain where VGT would be used prominently. 
In Study 2 Gaelic participants were asked to record each conversation, where a conversation was defined as a face-to-face interaction beyond an initial greeting. Indeed, previous observational studies (Birnie, 2018) have indicated that Gaelic greetings are common, even in non-Gaelic speakers, and that code-switching, normally from Gaelic to English, can take place after an initial greeting. This means that the language of the greeting is not necessarily a reflection of the language competences of the individuals involved in the interaction. Ingeborg asked Gaelic participants to delineate conversations by a change in participants, a change in language or a change in subject. Participants were provided with an example of a completed diary, which included the information that they were expected to provide and also provided an example of how to record any interactions where there was a change of language but where the participants and the topic remained the same.

In both studies participants were free to provide as much or as little information as they were comfortable with, using their preferred language for the entries. In Study 1, all diary entries (both those on paper and electronic) were in Dutch, and some were in English. Signs were not represented in the diaries, neither in glosses, pictures or make-shift notations. This is most likely linked to the mode of the diaries (pen and paper), affecting language choice. In Study 2, eight out of the eleven diaries were completed in Gaelic, with the remainder in English.

Analysing and evaluating the diary entries

We both provided instructions on how to complete entries where multiple languages or modalities were used, although participants created their own notations. The one-dimensional nature of the diaries and the organisation of the template meant that, in instances where participants indicated that more than one language or modality was used in interaction, it was difficult to ascertain the extent to which each of these was used. This raised questions around 
the perception of language use and language ideology of participants. In Study 2, for example, some Gaelic participants would consider the inclusion of one word or phrase as being inclusive of that language, while others focussed on including only the main language of the interaction. Ingeborg decided that all instances where multiple languages were included in the entry these would be treated as at least having occurred equally in the interaction if it could not be ascertained to what extent each of the languages featured in the interaction. However, as Starks and Lee (2010) concluded about their mixed code entries, it indicates that participants in the study have an awareness of their use of language.

Study 1 did not provide information on how to name or label the codes or languages in the diary. This meant that VGT participants were given ownership over the interpretation and conceptualisation of 'language'. However, given 'taal' (language) being the heading of the second column in the grid this might have influenced participants' view of what was expected. Maartje further explained to VGT participants that focus was on the use of their full semiotic repertoire and that they didn't have to stick to a bounded language-approach but could indicate when they were mixing different languages or modalities. Indeed, the distinct affordances of signed and spoken languages mean it is possible to simultaneously use linguistic features of for example Dutch and VGT. Depending on how features are blended, this has been called 'sign-speaking' (Zeshan \& Panda, 2018) but also 'Sign Supported Dutch' (or equivalents in other languages). 'Translanguaging' is another concept to refer to these practices, essentially referring to the mixing and blending of different languages (spoken languages, sign languages, or both) and/or modalities (for example signing, speaking, writing). For the deaf participants in Study 1 this was relevant since translanguaging is central to the deaf experience (De Meulder et al., 2019) and indeed often featured in the diaries, through participants employing different linguistic and semiotic resources 
simultaneously or alternated. For example, they would order French fries through writing in Notes on iPhone and using gestures with the shop assistant; communicate with the plumber using gestures, spoken Dutch words and writing; pick up their child from day-care and alternating signing to the child and speaking to the staff. In Study 1, because of lack of consistency across VGT participants, there was no quantitative analysis and each entry was analysed on a case-by-case basis.

Although VGT participants were actively encouraged to include written interactions, Gaelic participants were asked to only include spoken interaction 'characterised by spontaneous improvisation' with the choice of spoken language 'a reflex action rather than a result of reflexion' (Altuna \& Basurto 2013, p. 28). Some of the Gaelic participants also included a small number of email exchanges and social media messages. These were excluded from the analysis as the small numbers and lack of consistency across Gaelic participants meant that these could not be used to provide an indication of the wider linguistic practices of these individuals.

In both studies participants were asked to contact us once they had completed the diaries. We then collected the diaries and conducted a 'diary-focused interview') (Jones et al., 2000). These interviews were an essential element of the study and the diaries served as a prompt to evaluate and discuss linguistic practices of participants.

The majority of responses, in both studies, were single words or short phrases. A number of participants in both studies provided more detailed descriptions of their interactions or information about the context in which the conversation was conducted. The frequency with which participants in both studies recorded their information also varied. A number of participants completed the diary after each conversation whilst other entered the data at several fixed points per day, or at the end of the day. The timings of the diary 
completion are an important element when evaluating the entries. One of the issues identified with questionnaires or interview methods on collecting data on language use is retrospection and participants relying on recollecting events and situations. This also proved to be an issue in our studies although, perhaps, to a lesser extent. Participants who completed the diaries at the end of the day might not have been able to recall all the interactions which had taken place over the course of the day, especially shorter interactions which might not have been perceived as significant to the diarist. This retrospective completion of diaries might have resulted in participants omitting or forgetting entries or relying on '(benign) reconstruction or (deliberate) fabrication to complete missed entries' (Bolger et al., 2003, p. 594). In

questionnaires or even interviews, retrospection can cover a long period, and this can result in an aggregate response - which can be reflected in a Likert scale style answer. In the language diaries this retrospection is more likely to cover a shorter period of time, a couple of hours or a day. While the retrospective completion of the diaries might have resulted in a loss of detail in the entry itself, these details or additional information were in a number of instances provided during the follow-up interview where these entries acted as a prompt.

Allowing participants to complete the diaries at a time that was convenient to them might have affected the number of entries but allowing ownership over the frequency of the entries is likely to have supported compliance with the expectations of the study.

\section{Evaluation of the usefulness of language diaries to evaluate language use and language choice}

Diaries give insight in (changing) linguistic practices and can act as trigger for further change 
The completed language diaries in both studies provided a rich and contextualised data set. Participants themselves indicated that they recognised the situational aspect of the diary, namely that it is a snapshot of a moment in time and place that is fluid. In Study 1, several VGT participants commented that their diary would have been very different if they had completed it a few years or even just several months ago, because of changes in employment status, relationships, and other external factors. Callum, in Study 2, stated that his linguistic practices had changed significantly as a result of becoming involved in the Gaelic sector prior to the language diary study. This was the same for Catherine, who said that previous to her current employment she would not have used Gaelic as extensively as she was reporting now.

In Study 1, a number of the participants indicated that the diary results were surprising for them in terms of how much more VGT they used than they would have thought before completing the diary.

I am shocked actually that I use a lot of sign language, I had expected this to be less. My partner is hearing but I use sign language daily, I'm lucky my family is deaf. I also feel I have more contact with deaf people again [...]. If you had asked me five years ago to keep a diary that would have been very different, much less signing, that was a period I worked really hard and I didn't often meet deaf people. (Alexander)3

The use of the term 'lucky' and the surprise at the amount of signing demonstrates that for participants this is a positive surprise. In a follow-up interview, participant Marieke commented that this surprise at the amount of signing actually made her aware of her 'privilege' (sic), of how lucky she was to be able to sign so often, because she realized that for a lot of deaf people this is not the case.

For other participants in Study 1, the higher than expected use of VGT acted as a trigger for changing linguistic practices, as for example indicated by Delphine:

[...] my first reaction on seeing the full diary is that I have to go look for more LSFB (French Belgian Sign Language). I don't want VGT to become more dominant.

${ }^{3}$ All translations from VGT to English done by Maartje. 
When I see there are so few interactions in LSFB and more in VGT, then I get the feeling that I want more LSFB because that is the real me. VGT is not me. Because it [= the diary] has made me more aware of this, I want to go and look for more opportunities to use LSFB; I want to increase that. I didn't expect this at all.

Delphine's first sign language is LSFB. She started to use VGT because of her employment in the VGT sector and because she lives in Flanders and has Flemish friends. This realization that VGT was actually dominant led to a change in linguistic practices. When Maartje met her a year after the diary completion, Delphine was doing more translation work from French to LSFB.

Interestingly, in Study 2 the opposite was the case, with participants indicating in the interviews that they thought they used more Gaelic than was evident from their diary entries. Lucy, for example, who has three children all of which attend Gaelic Medium Education, indicated that she thought she was using a lot more Gaelic with her children in the house than appeared to be the case when the diary entries were discussed. Lucy became aware that there were many exceptions to her use of Gaelic with her children, when telling her children off, for example, she would only use English as she did not want the children to have negative associations with Gaelic.

Diaries allow for contextualized examples of language use and language choice

Iain, a participant in Study 2, indicated in the first interview that Gaelic was the predominant language used in his workplace. It was only when completing the diaries that he realised that although Gaelic was indeed used extensively in the work environment, there were also a number of instances where English was used, even in situations where all individuals could speak Gaelic:

Sometimes... you know ... sometimes, when something goes wrong with the computer or the printer or something ... it is easier to explain it in English than try and find the words in Gaelic. 
This example shows an awareness of why the language choice is made (to explain a technical matter), but only after completion of the diary. It is likely that Iain would have indicated that Gaelic was used 'all the time' or 'most of the time' if he had been asked to report on its use in the workplace through a questionnaire. It was the contextualised examples that allowed him to clearly reflect on the individual instances and how and why the language changed from Gaelic to English. Alexander, a participant in Study 1, mentioned a similar example. In the first interview he mentioned that at home with his deaf parents, he 'mostly' uses VGT. From one of his diary entries however, it appeared that sometimes VGT was used alongside other languages and modalities (in this case, speaking Dutch), and that this could alternate in the space of a single conversation.

During dinner we are often inclined to speak because that way we can eat faster (laughs). Also, my parents always watch the news during dinner; if we talk about the news we sign, if we talk about something else, we speak.

This again shows awareness of why the language/modality choice is made: VGT to 'eat faster' and to discuss specific subjects about the news on tv; spoken Dutch (or signspeaking) to talk about other topics not related to the news (e.g. the weather). Another example of what drives language and modality choice is from Johan, a participant in Study 1 and a deaf parent. When having lunch with his hearing son (a toddler), he notes 'Kobe signs more VGT while we eat - talks more Dutch while playing (shouting)', and further remarks that 'Kobe signs better when his mouth is full ; $^{\prime}$. Here, pragmatics (in this case being engaged in an activity) drive language and modality choice.

Another example of contextualized language use and language is again from Delphine. While on the way to a holiday, she had been texting in English with an American deaf friend who was house-sitting, giving her some instructions on housekeeping matters. When her friend asked how the oven worked, however, Delphine replied with a video in American Sign Language (ASL) (Figure 3). 
In the diary, she commented that this did not work well in written English and that ASL was 'much better' to explain the visual oven display. Delphine, who uses LSFB and ASL at home, also sometimes speaks French to her hearing son, for example while he is dressing or when she is telling a bedtime story in a darkened room. In the interview she clarified that this choice was partially pragmatic, citing reasons of efficiency in communication, but that ideology also played a part as she wants her son to have enough exposure to French, an important language in her life, and because she likes to use speech in some contexts.

The diaries proved to be a useful tool to evaluate the different factors which are driving language use and language choice, and how these are sometimes led by pragmatism rather than by language ideology; a point also raised by Lucy in Ingeborg's study who indicated that she didn't always have the right vocabulary to use and that she would then use English rather than Gaelic with her children.

\section{Benefits and limitations of language diaries as a method}

\section{Benefits}

Our respective studies highlight some benefits of using language diaries as a research method to evaluate language use and language choice and investigate multilingual practices (also highlighted by Jones et al., 2000, and Starks \& Lee, 2010). Diaries are a useful 
additional source of data combined with other methods such a surveys, interviews or language portraits. In interviews, diaries can act as a prompt to discuss and evaluate the linguistic practices of participants. While in surveys or interviews respondents might answer for example that they use a specific language 'almost always', the diaries give a more detailed insight into linguistic practices and contextual examples of when and what language or mixed code is used where, and why. Diaries are also helpful to understand specific factors that drive language and modality choice such as pragmatics, ideologies, content of a conversation, and use of assistive hearing technologies. While in language portraits participants discuss their emotions linked to learning and using languages and modalities now, in the past, and the future (Kusters \& De Meulder, 2019), diaries are about the here and now, which is also informed by participants' experiences in the past, and their aspirations for the future (e.g. when triggering a change in linguistic practices).

In Ingeborg's study the language use diaries served to create an understanding of the choice of language; this indicated that this was dependent only on the (already) established linguistic norms rather than the physical space in which the interaction took place; this means that language use between a group of speakers in public spaces was likely to be the same as the language used in private, or intimate domains.

Another crucial benefit is that diaries are less intrusive than filming (although with the development of ever smaller equipment like smartphones and small cameras filming is becoming less intrusive). The self-reporting nature allow for data to be collected in a number of different domains and situations, including those where access might be difficult to negotiate or rely on a high level of trust between the participant and the researcher. As a researcher we don't often get access to participants' bedrooms, bathrooms, dining tables, doctor visits, or family gatherings. While asking participants to audio-record or film themselves for a number of consecutive days might have led to more finetuned data, the 
chances of participants willing and able to do this are small, especially in the case of filming (necessary for sign language).

The open nature of responses means that diaries give insight in language ideologies participants do not have to restrict their comments to predefined categories. Because of their situated nature, diaries give insight in how language use can change through personal circumstances. This also shows that concepts like 'the language one uses most often' or 'knows the best', the language 'used at home' or 'preferred language', etc. are situated and fluid concepts.

For deaf people specifically, diaries allow participants to show how they use their full semiotic repertoire. With a researcher present, especially another signing deaf researcher, they might be more inclined to show their language loyalty to VGT or present a different persona, and for example use signs or gestures with a shop assistant while otherwise they would just speak.

\section{Limitations}

Language diaries rely on reported language use and thus come with all the limitations associated with reported language use (see also Starks \& Lee, 2010; Sundqvist \& Sylvén, 2014). In our studies they also came with the limitations of a diary to be completed in a written format. In Maartje's study the diary entries reflected the (potentially complex) multimodal nature of communication of both deaf and hearing signers. This means that where participants noted that VGT was used, this was, in practice, often more complex and might also have included other modalities. Sometimes, participants explicitly mentioned this, by noting "VGT + Dutch", "VGT, Dutch", "spoken Dutch + VGT”, “spoken Dutch with person $\mathrm{X}$ and VGT with person Y", "signing with speaking Dutch", "VGT/spoken Dutch", "spoken 
Dutch + signs", etc. Ingeborg's study Gaelic participants were faced with a binary choice of using either English or Gaelic, whether in distinct interactions or as part of the same conversation (code-mixing). The interviews were an opportunity to clarify and discuss these diary entries although this, too, relied on retrospection.

Allowing participants to determining their own coding was both a strength and limitation in terms of the validity of the study; it revealed the participants' language practices and ideologies but also made the dairy entries more complex to analyse; Ingeborg decided in each of the instances the extent to which Gaelic or English was used, while Maartje analysed entries on a case by case basis and tried to clarify this in the follow-up interview. Linguistic practices are messy by default, and diaries alone do not capture this. We agree with Starks and Lee (2010) that diaries are useful to investigate mixed codes in that they can be used to demonstrate how linguistic and semiotic repertories are used and that this goes beyond the use of a bounded 'language'.

Personal ideologies also played a role in how the linguistic practices were reported on in the diaries. It is likely that the ideological stance of individuals might have played a role in the reporting of language. An example would be Callum in Ingeborg's study who indicated a high level of code-switching in the diary - reporting that both English and Gaelic were used in a high proportion of the interactions (see Figure 9).

[Figure 5]

As in Maartje's study, it is not clear if this was reporting on actual de facto linguistic practices or whether this was an indication of an ideological stance towards Gaelic; Callum had recently changed careers and moved to a Gaelic sector job and felt strongly about the promotion of the language. This might have influenced the high level of mixed code reported. 
No information was solicited around the length of the interaction and, therefore, it was difficult to ascertain whether Callum was referring to the equal use of English and Gaelic in his diary or whether, in fact, the occasional use of Gaelic words and phrases was reported on as code-switching.

\section{Further methodological considerations}

We concur with Starks and Lee's findings (2010) that the main advantage of language diaries is that they are useful pilots for future ethnographic work as they provide details about where language exchanges are frequent and what languages are used in different contexts. This type of information is helpful in the design of in-depth ethnographic studies.

A specific methodological consideration is how to make the method more multimodal instead of relying on written entries alone. Allowing participants to keep a diary in a smartphone app for example might allow them to be more flexible about the language or modality they use for keeping the diary. It could also possibly also trigger use of emojis or GIFs. An option here would be to use existing journaling apps. Another consideration is to expand this method beyond diary-keeping. One idea would be to develop a smartphone application that would enable multilingual speakers to see how much time they spend speaking, signing, or writing different languages.4 The app could automatically record voice, signing or writing at random intervals, and provide period mini-reports against the background of basic demographic information and place of residence and speakers' perception of how much they use each language. The app could use GPS-tracking to track

\footnotetext{
${ }^{4}$ We are indebted to Dave Sayers for this idea: https://www.academia.edu/34427157/Outline_proposal_for_a_phone_app_to_gauge_language_use and_sociolinguistic_vitality
} 
participants' movements and see where they use each language, and incorporate Google Translate featuring automatic language recognition. The ethical and practical aspects of this method (e.g. how to position phone for clear enough recording throughout the day) would have to be carefully discussed. A further issue surrounding the use of digital technologies is that of participant ownership of the data. One of the strengths of this research was that the participants were free to record as much or as little information in the diaries as they felt comfortable with, at a time that was convenient to them. The use of digital technologies, or the use of prompts to trigger the recording of information (e.g. Plowman et al., 2011) might be considered invasive and disruptive and act as an in situ reminder of linguistic practices; making participants hyper-aware of their practices and potentially changing the language(s) used in the interaction.

\section{Acknowledgments}

Thank you to Michael Hornsby, Luk Van Mensel, Annelies Kusters, and the two anonymous reviewers from Language Awareness for their comments on previous versions of this manuscript.

\section{References}

Altuna, O., \& Basurto, A. (2013). A guide to language use observation survey methods. Vitoria-Gasteiz: Eusko Jaurlaritzaren Argitalpen Zerbitzu Nagusia. http://www.soziolinguistika.eus/Gida

Bartlett, R., \& Milligan, C. (2015). What is diary method? London: Bloomsbury. 
Birnie, I. (2018) Gaelic language use in public domains. In M. MacLeod \& C. SmithChristmas (Eds.), Gaelic in Contemporary Scotland: The Revitalisation of an Endangered Language (pp. 128-140). Edinburgh University Press.

Bolger, N., Davis, A., \& Rafaeli, E. (2003). Diary methods: Capturing life as it is lived. Annual Review of Psychology, 54(1), 579-616.

Bourhis, R.Y., \& Sachdev, I. (1984). Vitality perceptions and language attitudes: Some Canadian data. Journal of Language and Social Psychology, 3(2), 97-126.

de Bres, J., \& Franziskus, A. (2014). Multilingual practices of university students and changing forms of multilingualism in Luxembourg. International Journal of Multilingualism, $11(1), 62-75$.

Gibbons, J. (1987). Code-mixing and code choice: A Hong Kong case study. Multilingual Matters.

De Meulder, M., Werner, E., \& De Weerdt, D. (2017). Comparing minority languages - a case study of Flemish Sign Language and Upper Sorbian. European Journal of Minority Studies, 10(3-4), 285-321.

De Meulder, M., Kusters, A., Moriarty, E., \& Murray, J. J. (2019). Describe, don't prescribe. The practice and politics of translanguaging in the context of deaf signers. Journal of Multilingual and Multicultural Development, 2(2), 1-15.

De Meulder, M., \& Haesenne, T. (2019). A Belgian compromise? Recognising FrenchBelgian Sign Language and Flemish Sign Language. In M. De Meulder, J.J. Murray, \& R. McKee (Eds.), The legal recognition of sign languages. Advocacy and outcomes around the world (pp. 284-300). Multilingual Matters.

Dunbar, R. (2011). Bilingualism: Conceptual difficulties and practical challenges. In J. M. Kirk \& D. P. Ó Baoill (Eds.), Strategies for Minority Languages: Northern Ireland, the Republic of Ireland and Scotland (pp. 150-163). Cló Ollscoil na Banríona. 
Fishman, J. (1991). Reversing language shift: Theoretical and empirical foundations of assistance to threatened languages. Multilingual Matters.

Hyers, L. L. (2018). Diary methods. Understanding qualitative research. Oxford University Press.

Jones, K., Martin-Jones, M., \& Bhatt, A. (2000). Constructing a critical, dialogic approach to research on multilingual literacies. In M. Martin-Jones \& K. Jones (Eds.), Multilingual Literacies (pp. 346-378). John Benjamins Publishing Company.

Kusenbach, M. (2003). Street phenomenology: The go-along as ethnographic research tool. Ethnography, 4(3), 455-485.

Kusters, A., \& De Meulder, M. (2019). Language Portraits: Investigating Embodied Multilingual and Multimodal Repertoires. Forum: Qualitative Social Research, 20(3). DOI: 10.17169/fqs-20.3.3239

Lamarre, P. (2013). Catching "Montréal on the Move" and challenging the discourse of unilingualism in Québec. Anthropologica, 55, 1-16.

Lawson, S., \& Sachdev, I. (2000). Codeswitching in Tunisia: attitudinal and behavioural dimensions. Journal of Pragmatics, 32, 1343-1361.

MacKinnon, K. (1977). Language, education and social processes in a Gaelic community. Routledge

MacLeod, M. (2008). Gaelic language skills in the workplace. In J.M. Kirk \& D.P. Ó Baoill (Eds.), Language and economic development. Northern Ireland, the Republic of Ireland, and Scotland (pp. 134-152). Cló Ollscoil na Banríona.

Matthijs, L., Hardonk, S., Sermijn, J., Van Puyvelde, M., Leigh, G., Van Herreweghe, M., \& Loots, G. (2017). Mothers of deaf children in the 21st century. Dynamic positioning between the medical and cultural-linguistic discourses. The Journal of Deaf Studies and Deaf Education, 22(4), 1-13. 
McLeod, W., \& O'Rourke, B. (2015). "New speakers" of Gaelic: perceptions of linguistic authenticity and appropriateness. Applied Linguistics Review, 6(2), 151-172.

Mitchell, R.E., \& Karchmer, M.A. (2004). Chasing the mythical ten percent: Parental hearing status of deaf and hard of hearing students in the United States. Sign Language Studies, 4(2), 138-168.

Munro, G., Iain Mac an Tàilleir (Eds.) (2010). Coimhearsnachdan Gàidhlig An-diugh/Gaelic Communities Today. Dunedin Academic Press.

Myers-Scotton, C. (1988). Code switching as indexical of social negotiations. In M. Heller (Ed.), Codeswitching, anthropological and sociolinguistic perspectives (pp. 151-186). Mouton de Gruyter.

Nandi, A. (2016). Language policies on the ground: Parental language management in urban Galician homes. Unpublished PhD dissertation, Heriot-Watt University.

National Records of Scotland (2013). https://www.nrscotland.gov.uk/news/2013

NicAoidh, M. (2006). 'Pròiseact Plana Cànain nan Eilean Siar: A' chiad ìre - rannsachadh air suidheachadh na Gàidhlig anns na h-Eileanan Siar'(The language planning project in the Western Isles: the first stage - investigating the state of Gaelic in the Western Isles). In W. McLeod (Ed.), Revitalizing Gaelic in Scotland. Policy, planning and public discourse (pp. 73-86). Dunedin Academic Press.

Palmer, V. (1928). A new research manual for the study of local groups and communities. Journal of Educational Sociology, 2(2), 117-118.

Pennington, M., Sachdev, I., \& Lau, L. (2014). Language use by London Bangladeshi and Chinese adolescents: Some language diary data. In D. Abendroth-Timmer \& E.-M. Hennig (Eds.), Plurilingualism and multiliteracies: International research on identity construction in language education (pp. 71-87). Peter Lang. 
Place, S., \& Hoff, E. (2011). Properties of dual language exposure that influence 2-year-olds' bilingual proficiency. Child Development, 82(6), 1834-1849.

Plowman, L., Stevenson, O., McPake, J., Stephen, C., \& Adey, C. (2011). Parents, preschoolers and learning with technology at home: some implications for policy. Journal of Computer Assisted Learning, 27(4), 361 - 371.

Romaine, S. (1983). Collecting and interpreting self-reported data on the language use of linguistic minorities by means of 'language diaries'. M.A.L.S. Journal, 8, 3-30.

Scottish Parliament (2005). Gaelic Language (Scotland) Act 2005.

https://www.legislation.gov.uk/asp/2005/7/contents

Smith-Christmas, C. (2016). Family language policy: Maintaining an endangered language in the home. Palgrave MacMillan.

Starks, D., \& Lee, J. (2010). Rethinking methodology: what language diaries can offer to the study of code choice. Language Awareness, 19(4), 233-248.

Sundqvist, P., \& Sylvén, L. K. (2014). Language-related computer use: Focus on young L2 English learners in Sweden. ReCALL, 26(1), 3-20.

Ure, J. (1979). Language choice and socialisation in a multilingual community: Language use among primary school teachers in Ghana. In W. MacCormack \& S. A. Wurm (Eds.), Language and society: Anthropological issues (pp. 263-283). Mouton.

Urla, J. (2013). In O. Altuna \& A. Basurto (Ed.), Survey methods - A guide to language use observation survey methods. Vitoria-Gasteiz: Eusko Jaurlaritzaren Argitalpen Zerbitzu Nagusia.

Van Herreweghe, M., \& Vermeerbergen, M. (2004). Flemish Sign Language: Some risks of codification. In M. Van Herreweghe \& M. Vermeerbergen (Eds.), To the lexicon and beyond. Sociolinguistics in European deaf communities (pp. 111-137). Gallaudet University Press. 
Zeshan, U., \& Panda, S. (2018). Sign-speaking: The structure of simultaneous bimodal utterances. Applied Linguistics Review, 9(1), 1-34.

\section{Figures}

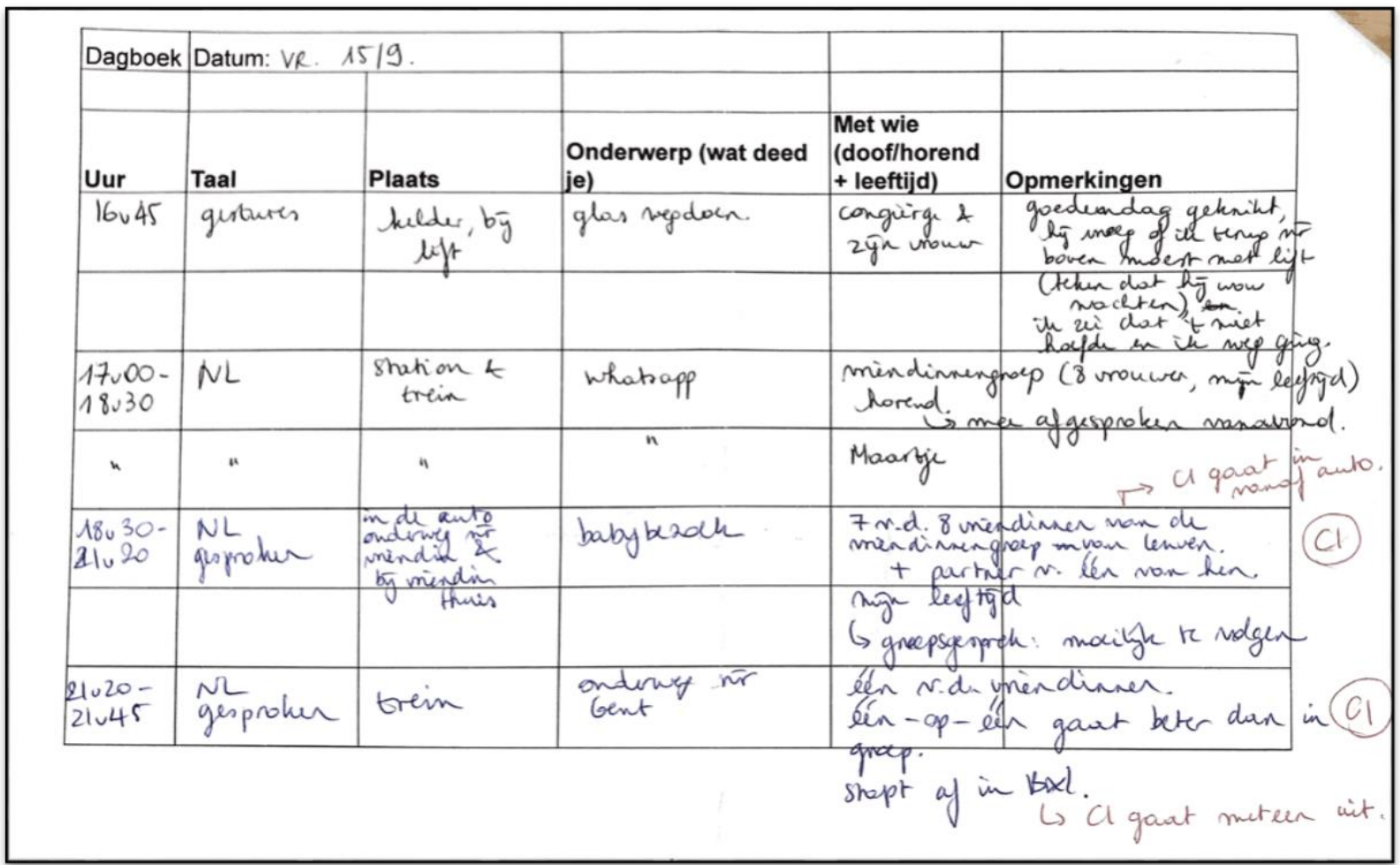

Figure 1 
Ceann-latha: Dimaint 27 Faolleach



Fiosrachadh a bharrachd

$$
\text { Tha mi a'mothachadh gu bheil ni a'cleachdadh }
$$
barachd Bewra ris a' Chawn as sine maw a tha mi a'trod mutha. Bha atganad aig an righean ag an agus bha i mi-thoilichte



a 'feucham $i$ Gaidhlig a chleachdadh. Nuai a bha mi beag, bra na searn antaichean agan a' geavan nach vals b'e cànan mai bhian an Beuta aison tiod is cuideigin?

Figure 2 
Ceann-latha: Diardaoin 12/2/15

\begin{tabular}{|c|c|c|c|c|c|c|c|c|c|}
\hline \multirow{3}{*}{ Aite no suidheachadh } & \multicolumn{6}{|l|}{ Com-pàirtichean } & \multirow[t]{3}{*}{ Cuspair } & \multirow{2}{*}{\multicolumn{2}{|c|}{ Cànan }} \\
\hline & \multirow[t]{2}{*}{ Dàimh } & \multicolumn{3}{|c|}{ Aois } & \multicolumn{2}{|c|}{ Gnè } & & & \\
\hline & & $\begin{array}{l}\stackrel{m}{v} \\
\mathrm{v}\end{array}$ & $\begin{array}{l}8 \\
1 \\
8 \\
\end{array}$ & $\begin{array}{l}8 \\
\wedge \\
\end{array}$ &  & 递 & & $g$ & 章 \\
\hline Taigh & Màthair & & $\mathrm{X}$ & & & $\mathrm{X}$ & Còmhradh àbhaisteach & $x$ & $\mathrm{X}$ \\
\hline Obair- & Luchd-obrach & $\mathrm{X}$ & $\mathrm{X}$ & & $\mathrm{X}$ & $\mathrm{X}$ & Còmhradh àbhaisteach/obair & $\mathrm{X}$ & $\mathrm{X}$ \\
\hline Lunch & Caraid & $\mathrm{X}$ & & & & $\mathrm{X}$ & Còmhradh àbhaisteach & $\mathrm{X}$ & $\mathrm{X}$ \\
\hline Obair- & Luchd-obrach & $\mathrm{X}$ & $\mathrm{X}$ & & $\mathrm{X}$ & $\mathrm{X}$ & Còmhradh àbhaisteach/obair & $\mathrm{X}$ & $\mathrm{X}$ \\
\hline Taigh mo charaid & Caraid / Flatmate & $\mathrm{X}$ & & & $\mathrm{X}$ & $\mathrm{X}$ & Còmhradh àbhaisteach & $\mathrm{X}$ & $\mathrm{X}$ \\
\hline Taigh & Màthair & & $\mathrm{X}$ & & & $\mathrm{X}$ & Còmhradh àbhaisteach & $\mathrm{X}$ & $\mathrm{X}$ \\
\hline Ionad Spòrs & Caraidean & $\mathrm{X}$ & & & $\mathrm{X}$ & $\mathrm{X}$ & Spòrs/fallain & $\mathrm{X}$ & $\mathrm{X}$ \\
\hline & & & & & & & & & \\
\hline & & & & & & & & & \\
\hline & & & & & & & & & \\
\hline
\end{tabular}

Fiosrachadh a bharrachd

'S e companaidh Gàidhlig a th

Tha Gàidhlig aig mo charaid ach chan eil Gàidhlig aig am flat mate aige, 's e Eireannach a th' innte.

Figure 5

\section{Figure captions}

- Figure 1: Example of participant diary in the VGT study. Translation of column headings: time of the day/language/place/topic (what did you do)/with whom (deaf/hearing + age)/comments.

- Figure 2: Example of participant diary in the Gaelic study. Translation of the column headings: place or situation/relationship/age/gender/topic/language.

Figure 5: Extract from a participant diary from the Gaelic study. 